\begin{tabular}{|c|c|c|c|c|c|}
\hline MUNIBE Antropologia-Arkeologia & $n^{\circ} 71$ & $103-120$ & DONOSTIA & 2020 & ISSN 1132-2217 • eISSN 2172-4555 \\
\hline
\end{tabular}

\title{
Los denticulados del yacimiento de Aizpea (Arive, Navarra): análisis de huellas de uso e interpretación funcional
}

\author{
The denticulates from the site of Aizpea (Arive, Navarre): \\ use wear analysis and functional interpretation
}

PALABRAS CLAVES: Análisis funcional, muescas y denticulados, Mesolítico final, Neolítico antiguo.

GAKO-HITZAK: Analisi funtzionala, hozkadurak eta dentikulatuak, Mesolito amaiera, antzinako Neolitoa.

KEY WORDS: Use-wear analysis, notches and denticulates, Late Mesolithic, Early Neolithic.

MARÍA AMPARO LABORDA MARTÍNEZ(1)

\section{RESUMEN}

En este trabajo se presentan los resultados del análisis funcional de las láminas y lascas con muescas o denticuladas, procedentes de los niveles del Mesolítico final y Neolítico antiguo del yacimiento de Aizpea (Arive, Navarra). Las microhuellas identificadas han permitido un preciso diagnóstico funcional para reconstruir la manera en que estos útiles fueron utilizados y el tipo de materias trabajadas. Este estudio ha revelado también la idoneidad de la aplicación de la metodología traceológica para inferir técnicas de transformación de distintos recursos. El trabajo de la madera y el hueso fueron las actividades realizadas con denticulados en Aizpea, obviamente relacionados con las estrategias de subsistencia de los grupos que ocuparon el abrigo en diferentes momentos entre el VIII y la primera mitad del VII milenio BP.

\section{LABURPENA}

Lan honetan Mesolito amaieran eta antzinako Neolito garaian Aizpeako aztarnategian (Aribe, Nafarroa) hozkadura- eta dentikulatu-aztarnak dituzten lamina eta harri-printzen analisi funtzionalaren emaitzak aurkeztu dira. Identifikatutako mikroaztarnek tresna horiek nola erabili ziren eta zer-nolako lanak egin zituzten berreraikitzeko diagnostiko funtzional zehatza egiteko aukera eman dute. Era berean, ikerketa honek erakutsi du metodologia trazeologikoa aproposa dela hainbat baliabideren eraldaketa-teknikak ondorioztatzeko. Aizpean dentikulatuekin egurra eta hezurra lantzen zen, eta horrek lotura argia du VIII. mendearen eta VII. mendeko bigarren erdiaren (BP milurtekoa) arteko hainbat unetan babesleku horretan bizi izan ziren taldeen biziraupen-estrategiekin.

\section{ABSTRACT}

The site excavated in Aizpea offers a model about the ways of life of the last groups of prehistoric hunter-gatherers who lived in a Pyrenean environment, in the north of Navarre, during the Late Mesolithic and the beginning of the Neolithic (Barandiarán \& Cava, 2001). Whoevers took refuge in this rock-shelter exploited a wide range of resources from different ecosystems, which were close to the site: a wide spectrum of ungulates they were hunted; they fished barbel and trout at the next Irati river, and they also took advantage of a varied representation of plants remains that were been used for food or fuel. The flaked lithic assemblages that they have produced are mainly composed of microlithic elements, geometrics, small blades and backed points. On the other hand, numerous denticulates and, in smaller proportions, scrapers, racloirs, truncations or drills make up the domestic toolkit. Within the industrial dynamic of Aizpea, the evolution of the denticulates, as the third majority typological group, experiences a quantitative decrease from the oldest to the most recent stage. This paper present the results of a use-wear analysis concerning noched or denticulates blades and flakes recovered from the three phases established on the site, Aizpea I and II (geometric Mesolithic) and Aizpea III (early Neolithic). Once defined the state of conservation of the assemblage, a sample of this elements have been observed in the microscope. Some of them presented exclusively one notch, and others were characterized by a truly denticulated edge. The micro traces identified has allowed a precise functional diagnostic to reconstruct how these tools were used and the type of worked materials. The use-wear analysis has shown that these pieces are used as scraping tools. This study has also revealed the suitability of the apliccation of traceological methodology to infer transformation techniques of different resources. Wood and bone working were the activities performated with denticulates at Aizpea, obviously related to the subsistence strategies of the groups that occupied the rock shelter at different times between the VIIIth and first half the VIIth millennium BP.

\footnotetext{
(1) Universidad de Navarra. Campus Universitario, 31080. Pamplona, Navarra. ampalaborda@hotmail.es
} 


\section{INTRODUCCIÓN}

El progreso en el conocimiento de las formas culturales que se suceden en el tránsito del Mesolítico final al Neolítico antiguo en la vertiente surpirenaica y en la cuenca del Ebro ha sido notable en los tres últimos decenios. En este sentido, se conoce mejor la realidad cultural del Mesolítico de facies geométrica, la etapa más reciente del período homónimo, que interesa en este trabajo, y cuyo ámbito temporal en este vasto territorio se sitúa entre el VIII milenio BP y la primera mitad del VII milenio BP. También se ha enriquecido la comprensión de las bases de subsistencia, las diferentes estrategias de explotación del medio y los modos de vida de los últimos grupos de cazadores-recolectores (Cava, 1994; Alday, 2002; Alday y Cava, 2009; Utrilla et al., 2009; Soto et al., 2016).

La dinámica industrial de esta unidad la definen cambios tecnológicos que evidencian nuevas maneras de producir y gestionar los equipamientos líticos. Estas transformaciones constituyen un fenómeno generalizado en otras áreas geográficas como el Levante peninsular (Martí et al., 2009), manifestándose también en contextos del occidente europeo adscritos al geometrismo clásico tardenoide.

Uno de los rasgos distintivos de este complejo es el renovado interés por la tecnología laminar destinada, por un lado, a la fabricación de utillaje microlítico: dorsos y, sobre todo, armaduras geométricas. Por otro, al formateado de láminas con muescas o denticulaciones o con retoques continuos. La producción lítica se complementa con la talla de utensilios de sustrato, además de otros artefactos en soportes lascares y fragmentos irregulares, configurados mediante retoque denticulado, en muchos casos escamoso. Estas últimas piezas evidencian la perduración de modelos tecnotipológicos propios de una facies industrial mesolítica anterior, con una cronología del IX milenio y comienzos VIII milenio BP.

Por otra parte, la tecnología de talla desarrollada entrañó variaciones en la composición tipológica de los conjuntos líticos retocados (Alday y Cava, 2009). Pero la representatividad cuantitativa de los diferentes utensilios debió obedecer a la naturaleza de las actividades llevadas a cabo en cada asentamiento prehistórico y al propio uso que desempeñaron para satisfacer necesidades funcionales determinadas. A este respecto, los estudios traceológicos han aportado información válida para una diagnosis funcional de los integrantes de ciertos grupos tipológicos. Así ocurre con los elementos microlíticos, en particular las formas geométricas, que tuvieron una función muy específica como proyectiles (Domingo, 2005; 2009), constituyendo la mayor parte de los componentes del instrumental para la caza. También proporcionan referencias concluyentes acerca del empleo sobre materias duras orgánicas de los filos dentados de artefactos conformados de forma sumaria en lascas o trozos (Mazo, 2005).
Entre el utillaje laminar con retoque denticulado o con muescas, son estas últimas quienes han recibido una mayor atención. Desde el punto de vista tecnológico, las láminas con muesca se han considerado tradicionalmente como soportes utilizados en el proceso de consecución de armaduras geométricas mediante la técnica del microburil. Sin embargo, también existen propuestas que han concedido protagonismo a su estatus como utensilios. La más antigua es la formulada por J. G. Rozoy (1978: 969), en relación con las producciones laminares estandarizadas de «estilo» Montbani. Plantea la presumible utilidad de las muescas, originadas, a juicio del autor, durante el uso de los filos en la preparación de astiles de flecha. El interés sobre el significado funcional de estas piezas tomó un renovado impulso hace pocos años, en el marco de diversos proyectos de investigación colectivos, principalmente de ámbito europeo, que atañen a yacimientos franceses y belgas datados entre el VII milenio y VI milenio cal BC (Gassin et al., 2013; Gassin et al., 2014). A estas iniciativas se suma otra más reciente polarizada en el estudio de conjuntos de láminas procedentes de niveles mesolíticos de la facies geométrica y/o de muescas y denticulados individualizadas en diversos yacimientos de la cuenca del Ebro y del Mediterráneo peninsular (Mazzucco et al., 2016). Los interesantes resultados obtenidos confirman la condición de herramientas de uso directo de buena parte de láminas y laminitas con muesca o denticuladas, que sirvieron en tareas de raspado en una gama de materiales de diferente naturaleza como hueso, madera y piel. Especial interés reviste la utilización sobre plantas no leñosas, asociada a elaboraciones de cordelería y cestería, por cuanto revela la incipiente importancia del trabajo de las materias vegetales en el Mesolítico en diversas áreas geográficas de Europa (Caspar et al., 2005; Alday et al., 2012; Gassin et al., 2013), y que perdurará a inicios del Neolítico (Cahen y Gysels, 1983; Philibert et al., 2014).

\section{OBJETIVOS}

En el presente trabajo se aborda el análisis funcional, basado en el estudio de huellas microscópicas de uso, de los denticulados procedentes del depósito prehistórico de Aizpea (Arive, Navarra). Estas piezas junto con el mayoritario efectivo de elementos microlíticos -geométricos y dorsos- vertebran el grueso de la colección de objetos retocados (Cava, 2001). Y las oscilaciones de los índices relativos de ambas categorías industriales, además de las proporciones de elementos de sustrato, indican como variaron las preferencias técnicas y tipológicas en los tres horizontes culturales individualizados: Aizpea I (7790 770 y $7160 \pm 70$ BP) y Aizpea II (6830 $\pm 70 \mathrm{BP})$, adscritos al Mesolítico avanzado de facies geométrica, y Aizpea III (6370 \pm 70 BP), datado en el Neolítico antiguo.

Las diferencias en la composición de los diferentes equipamientos líticos registrados, y la entidad cuanti- 
tativa de los denticulados en cada uno de ellos quizá deban relacionarse con determinadas actividades que realizaron los grupos de cazadores-recolectores que se refugiaron en el abrigo. En este sentido, las distintas ocupaciones, sin ruptura estratigráfica alguna, y los usos de este abrigo rocoso de acampada temporal en las proximidades del río Irati, se han vinculado al aprovechamiento y recogida de diversos recursos de origen animal y vegetal, que ofrecían los biotopos del paisaje circundante al enclave prepirenaico y el propio cauce fluvial (Cava, 1997; Barandiarán y Cava, 2001).

Se ha comprobado que existen relaciones funcionales entre utillajes específicos estandarizados y las necesidades de subsistencia inmediata de los grupos durante las estancias en el lugar. Es el caso de los microlitos geométricos utilizados como proyectiles para cazar (Domingo, 2005), entre el instrumental lítico de sílex. Cabría añadir también las puntas y anzuelos rectos en materias óseas probablemente destinados a la pesca de truchas y barbos en el Irati (Barandiarán, 2001).

El interés de aplicar el análisis traceológico a los denticulados, metodología cuya idoneidad para reconocer una hipotética identidad funcional como instrumentos de trabajo de las láminas con muesca fue sugerida en la memoria del yacimiento (Cava, 2001: 137), se centra en determinar si fueron usados y, en tal caso, para qué sirvieron. En el estudio presente se trata de discernir el papel que este conjunto de piezas, menos elaboradas, desempeñaron en posibles actividades en las que pudieron haber participado, y que acaso fueron realizadas en el asentamiento.

\section{METODOLOGÍA}

Aunque los potenciales filos activos están conformados mediante retoque, se ha descartado el examen de estigmas a escala macroscópica, dada la problemática que concierne a la distinción entre los negativos de las extracciones intencionales de talla y los desconchados causados durante la práctica de distintos trabajos. El análisis se ha focalizado en la observación y el reconocimiento de huellas microscópicas de uso, en concreto, superficies pulidas, redondeamientos de los bordes y estrías.

En primer lugar, se procedió a inspeccionar las piezas con una lupa binocular (Carl Zeiss, con una magnificación estándar hasta 50X) para detectar eventuales residuos macroscópicos. Después se sometieron a una limpieza manual inocua con agua, eliminándose la sigla, cuando fue preciso, con acetona. Este mismo disolvente se empleó para hacer desaparecer las huellas de grasa de las sucesivas manipulaciones. Por último, el registro y descripción de las características de las huellas se llevaron a cabo a través de una observación a altos aumentos -100X y 200X-con un microscopio metalográfico (modelo Nikon Epiphot). En uno de sus oculares se adaptó una cámara digital Dino-Lite para la reproducción microfotográfica de los rastros laborales.
El análisis individualizado de las piezas se ha llevado a cabo de forma metódica conforme a una organización previa de las mismas. Estas se listaron en orden consecutivo según su sigla, agrupadas por tipos en el seno de cada uno de los horizontes culturales del yacimiento, del más antiguo al más reciente. Durante el registro propiamente dicho de los datos microscópicos, los relativos a los atributos de las diferentes huellas de uso se han detallado por cada una de las caras de los bordes activos.

Los resultados del análisis se exponen en una tabla (Cf. Fig. 2) que recopila y sintetiza los datos esenciales de cada artefacto, estructurados en cinco campos. El inicial recoge las alteraciones macro y microscópicas observadas. En el siguiente se consignan las piezas sin trazas de uso. El resto de los apartados conciernen a los elementos utilizados. En el primero de ellos se incluyen tres variables relativas a las zonas activas (si se hallan completas o no; delineación y ángulo de filo). A continuación, otro bloque de información contiene las huellas laborales microscópicas en las que se ha basado el diagnóstico de uso. Y el último, corresponde a la interpretación de la función, con una referencia subjetiva- al grado de confianza que se otorga a las determinaciones funcionales.

En el proceso de inferencia de uso se han aplicado criterios funcionales que han sido establecidos en diversos trabajos analíticos de naturaleza experimental (Plisson, 1985; Vaughan, 1985; González e Ibáñez, 1994; Laborda, 2010). Los datos obtenidos han permitido reconstruir la cinemática de los útiles y determinar, con diferente grado de precisión y fiabilidad, la dureza relativa y el tipo específico de materia trabajada.

Por otra parte, el conocimiento del contexto arqueológico y de los restos de actividades conservadas en el registro arqueológico (Barandiarán y Cava, 2001) han ofrecido también claves adicionales para interpretar la funcionalidad de estos útiles.

\section{LA MUESTRA}

De las 81 piezas denticuladas incluidas en la colección de utensilios retocados (Cava, 2001: 126), se han localizado $73(90,12 \%)$, de los cuales 36 corresponden al horizonte I, 26 al II y 11 a Aizpea III. A este recuento hay que añadir 8 efectivos más procedentes de la cata estratigráfica del yacimiento (nivel b, cuadro $5 A$ ), que no se contabilizaron en el estudio tecnotipológico, y cuya suma arroja un total de 81 piezas.

La selección para su estudio se ha encontrado con la dificultad del estado de conservación macroscópico de los materiales. Una parte de los componentes de la serie lítica, como se desarrollará más adelante, muestra signos de alteración térmica de la superficie silícea. Pero dado que el objetivo era llevar a cabo un análisis de huellas de uso del mayor número de elementos posibles, en la estrategia de muestreo aplicada tan solo 
se han excluido aquellos que presentaban pátinas blancas cubrientes que afectaban a los filos. Este tipo de alteración química enmascara y oculta potenciales rastros laborales microscópicos, imposibilitando su inspección a altos aumentos. Tras desechar 11 de ellos, la muestra analizada asciende a 70 objetos $(86,41 \%)$. En la Figura 1 se refleja la distribución por fases de las piezas estudiadas.

Entre los tipos primarios, según las categorías establecidas en el sistema de clasificación de J. Fortea para el Epipaleolítico (Fortea, 1973), dominan los elaborados en soporte laminar $(57,14 \%)$ (Fig. 1). Las piezas con muesca (MD3) son mayoritarias (48,57\%), con una proporción más cuantiosa en Aizpea II (44,11\%), respecto a los tramos inferior (32,35\%) y superior (11,76\%). En cambio, las láminas con retoque denticulado (MD4) apenas totalizan un 8,57\%. Los ejemplares formateados en lasca suponen un $42,85 \%$. Se han computado las variantes morfológicas con muesca (MD1) y denticuladas (MD2), y sus porcentajes oscilan entre un $12,85 \%$ y un $30 \%$ respectivamente. El último morfotipo constituye el grupo más numeroso por la presencia de sendos lotes de lascas denticuladas carenadas con retoques escaleriformes que provienen sobre todo de la base y, en menor medida, de la unidad intermedia de la secuencia de Aizpea.

La práctica totalidad de los denticulados de la muestra ha sido fabricada en sílex del Flysch, procedente de los afloramientos de Artxilondo. Se trata de un sílex de grano fino que presenta un color gris muy oscuro, a veces casi negro. Solamente un fragmento de una lámina con muesca, recuperada en Aizpea I, puede asimilarse a una escasa variedad traslúcida, identificada también entre las evidencias líticas (Tarriño, 2001: 53).

\begin{tabular}{|c|c|c|c|c|c|c|}
\hline \multirow{2}{*}{ TIPO } & Aizpea I & Aizpea II & Aizpea III & Cata & \multirow{2}{*}{ Total } & $\%$ \\
\cline { 2 - 6 } & $\mathbf{n}^{\mathbf{0}}$ piezas & $\mathbf{n}^{\mathbf{0}}$ piezas & $\mathbf{n}^{\mathbf{0}}$ piezas & $\mathbf{n}^{\mathbf{0}}$ piezas & & \\
\hline MD1 & 5 & 1 & 1 & 2 & 9 & 12,85 \\
\hline MD2 & 13 & 5 & 2 & 1 & 21 & 30 \\
\hline MD3 & 11 & 15 & 4 & 4 & 34 & 48,57 \\
\hline MD4 & 2 & 4 & - & - & 6 & 8,57 \\
\hline Total & 31 & 25 & 7 & 7 & 70 & 99,99 \\
\hline$\%$ & 44,28 & 35,71 & 10 & 10 & \multicolumn{2}{|c|}{99,99} \\
\hline
\end{tabular}

Fig.1. Muestra de denticulados analizada. / Sample of denticulates analyzed for wear traces.

\section{ESTADO DE CONSERVACIÓN}

El estado de conservación en algo más de la mitad de la muestra -se han contabilizado 41 piezas (58,57\%)- es en general bueno, por tanto, presentaba una aceptable disposición para el estudio funcional. Pero el 41,42\% restante de la colección ha sufrido alteraciones térmicas que, por otra parte, afectaban a casi todo el conjunto de la industria lítica (Tarriño, 2001:
53). Las consecuencias macroscópicas más comunes de haber estado en contacto con fuego son la transformación del color original gris oscuro del sílex en una gama de coloraciones grisáceas más claras y mates, y una cierta rugosidad superficial perceptible al tacto. Hasta 29 elementos, distribuidos principalmente en los horizontes I y II, mostraban estas afecciones ( $C$ f. Fig. 2). En 2 casos, la impronta de exposición al fuego ha quedado patente en las tonalidades rojizas de sus superficies. $Y$, en 4 más, por la presencia de manchas blanquecinas incipientes (Bustos y Baena, 2016), localizadas de manera aleatoria sobre todo en las caras dorsales. Otras huellas de termoalteración son escamaciones y/o cúpulas identificadas en una o ambas caras de 6 denticulados.

En principio, este lote de evidencias ofrecía limitadas expectativas para un examen microscópico en condiciones, ya que cabía esperar encontrar dificultades en la calidad de la observación, tal como se comprobó en el análisis funcional de los microlitos geométricos (Domingo, 2005: 29). A esta escala, se ha constatado durante la inspección que el aspecto de las superficies que han soportado el contacto directo con un foco de calor muestra numerosas manchitas blanquecinas y frecuentes brillos, de distribución caótica, que incrementan su reflectividad. A pesar de ello, dichos brillos se han diferenciado con cierta facilidad de los micropulidos de uso, cuya ubicación y grado de definición y desarrollo han permitido determinar su origen laboral. En esta línea, pruebas experimentales han demostrado que la apariencia y las características de ciertos micropulidos permanecen bastante inalterables, cuando los artefactos portadores de estas huellas sufren los efectos de estar expuestos a altas temperaturas. Así, aquellos generados por el trabajo de materias orgánicas duras son los más resistentes al impacto térmico (Clemente, 1997: 533-534).

También perceptibles a través del microscopio han sido plataformas de abrasión, planas y muy brillantes, en diferentes puntos interiores de 4 piezas y junto al borde retocado de otras 3 . Estos estigmas, que son el resultado de roces postdeposicionales producidos mientras los artefactos permanecieron en el relleno sedimentario, no han interferido, sin embargo, en una correcta visión. Tampoco han supuesto un impedimento ocular los brillos metálicos, fruto de las fricciones accidentales de instrumentos utilizados en la excavación, detectados en 2 piezas.

\section{RESULTADOS DEL ANÁLISIS TRACEOLÓGICO}

Los datos funcionales del conjunto de los 70 elementos examinados se presentan de forma sintética en la Figura 2. Entre ellos, mostraban rastros laborales 34, lo que supone un 48,57\% del total. Representados en la Figura 3, su distribución por fases manifiesta un descenso progresivo de los índices de uso de los denticulados, con una mayor representación -61,29\%- en la 


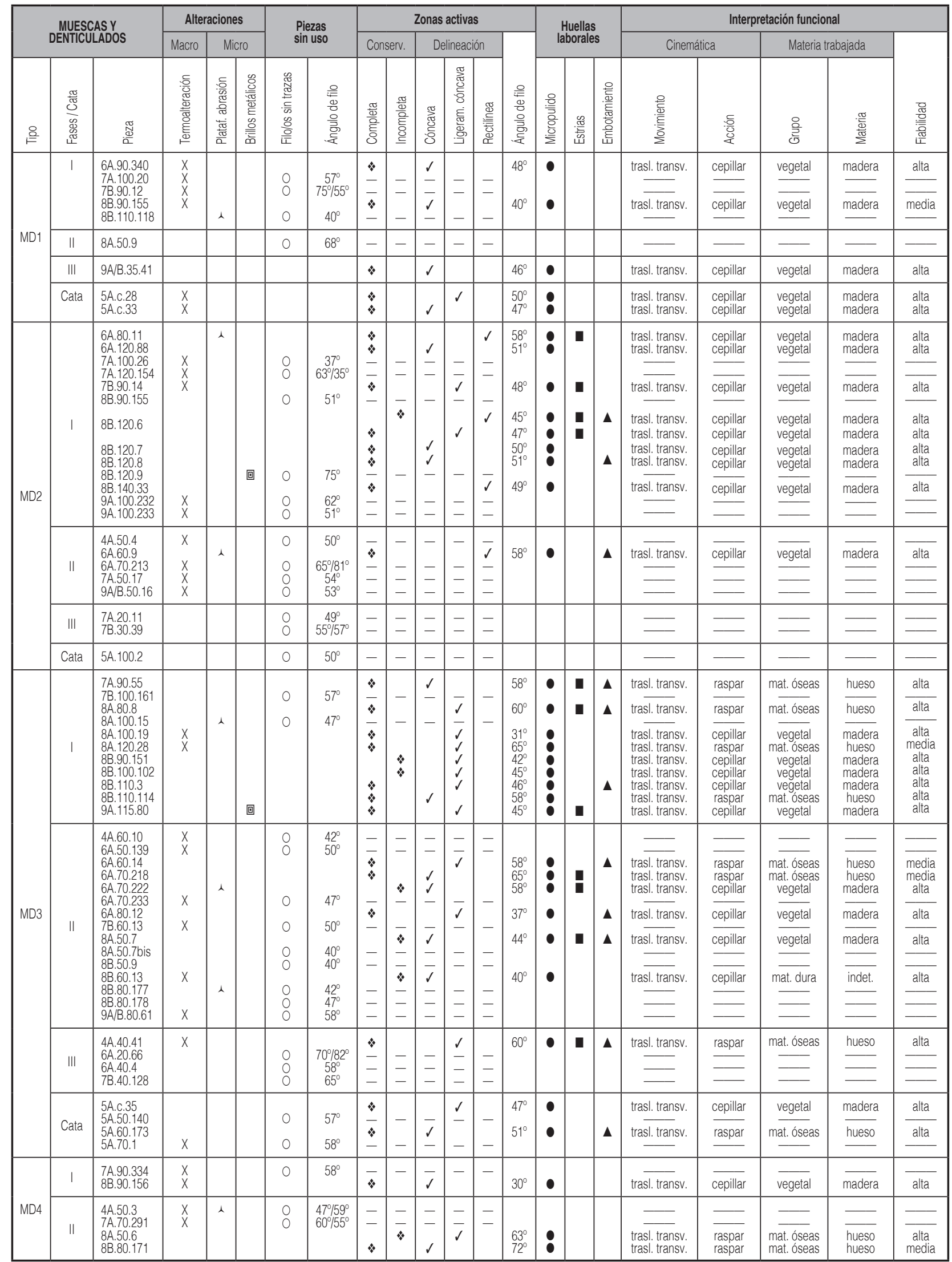

Fig.2. Resultados del análisis funcional. / Microwear analysis results. 

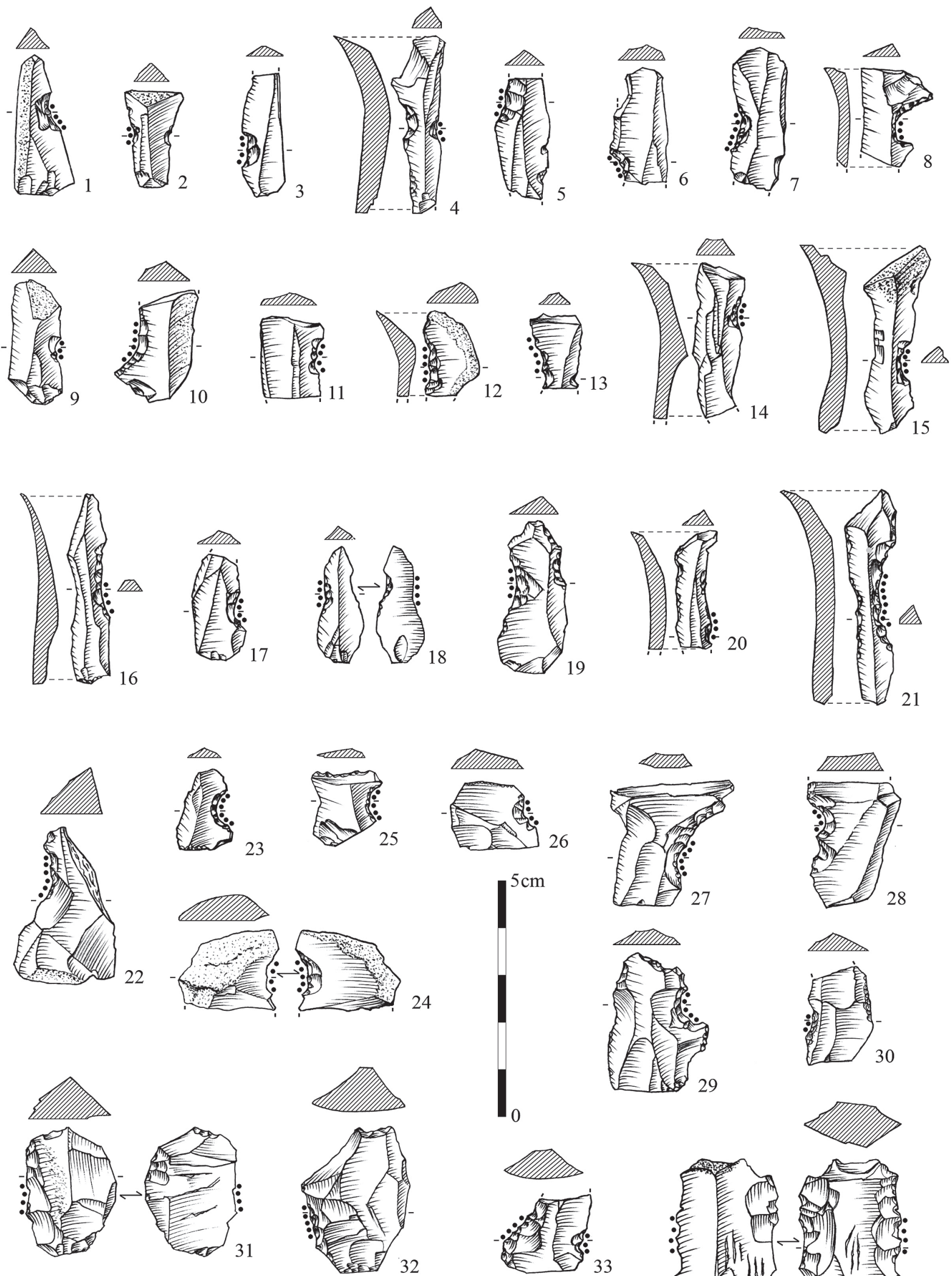

...... Huellas de uso
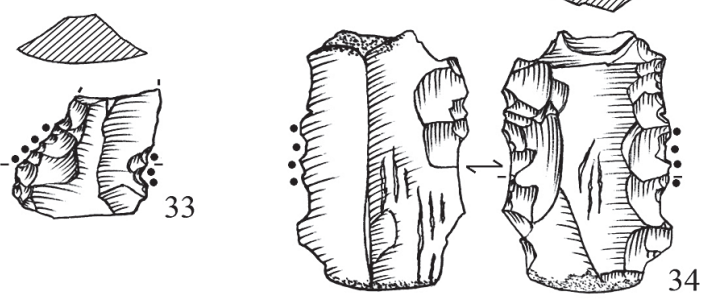

Fig.3. Piezas con huellas de uso. Aizpea I: núm. 1-9, 19, 22 y 23. Aizpea II: núm. 10-15, 20-21 y 27-33. Aizpea III: núm. 16 y 24. Sondeo estratigráfico: núm. 17, 18 y 25-26. / Pieces with traces of use. Aizpea I: No. 1-9, 19, 22 y 23. Aizpea II: No. 10-15, 20-21 y 27-33. Aizpea III: No. 16 y 24. Stratigraphic survey: No. 17-18 y $25-26$. 
más antigua del Mesolítico geométrico. El aprovechamiento de este tipo de útiles decrece de manera acusada $-36 \%$ - en el siguiente horizonte, Aizpea II, siendo aún más escaso -28,57\% - en la fase de ocupación del Neolítico antiguo (Fig. 4). En cada uno de los lotes con estigmas de trabajo, la reconstrucción de la cinemática ha sido posible en la totalidad de los elementos. Y los criterios funcionales han sido también de gran utilidad para inferir con suficiente fiabilidad las materias específicas trabajadas en el $82,85 \%$ de los filos que fueron empleados. Las determinaciones establecidas con un alto grado de confianza se reflejan en índices de identificación que oscilan entre un $89,47 \%$ en Aizpea I, un porcentaje del $66,66 \%$ en el tramo suprayacente, Aizpea II, y un 100\% en Aizpea III (Fig. 4).

\subsection{Los tipos utilizados. Características tecno- morfológicas}

\subsubsection{Láminas retocadas con muescas y denticuladas}

Las muescas con huellas de uso se han configurado principalmente en láminas, 14 piezas, la mayor parte procedentes de Aizpea I y II (Fig. 3.1, 4-8 y 1015); un ejemplar más de Aizpea III (Fig. 3.16) y otro del sondeo estratigráfico (Fig. 3.17). Por el contrario, son muy escasos otros soportes como lascas laminares y laminitas, con 2 ejemplares en cada caso (Fig. 3.2, 3, 9 y 18). Aunque las morfologías laminares casi enteras constituyen el porcentaje más alto (61.11\%), también hay fragmentos $(38,88 \%)$, correspondientes a segmentos cortos y distales (4), además de aquellos largos que conservan las partes proximales-mediales (2) o la medial-distal (1).

No es posible realizar un análisis métrico riguroso de estos soportes, dado lo reducido de la muestra. Así y todo, se han medido las tres dimensiones básicas, expresadas en milímetros: la longitud, de las piezas enteras o prácticamente completas; la anchura máxima, en las zonas que no han sido afectadas por el retoque, y, por último, el espesor.

La longitud conservada de las escasas láminas íntegras usadas que proceden de los tres estadios de ocupación del yacimiento no sobrepasa los $40 \mathrm{~mm}$, con una media de $35 \mathrm{~mm}$. Y respecto a los fragmentos en los que esta dimensión podría reconstruirse, se concentra en un intervalo métrico que incluye desde longitudes iguales o mayores a $24 \mathrm{~mm}$, hasta las superiores a $36 \mathrm{~mm}$. En las laminitas, la longitud fluctúa entre 25 y $26 \mathrm{~mm}$, y las lascas laminares enteras son igualmente cortas, con medidas variables entre $20,5 \mathrm{~mm}$ y $26 \mathrm{~mm}$.
Existe una variación en la media de anchura de las láminas de los tramos I y II, que está comprendida entre $11,5 \mathrm{~mm}$ en el primero y $10,7 \mathrm{~mm}$ en el siguiente. $Y$ en el horizonte III, se registra la lámina más estrecha del conjunto, con $7 \mathrm{~mm}$ de anchura. Por otra parte, hay que consignar la anchura media de 11,2 mm de los dos soportes clasificados como lascas laminares, hallados en Aizpea I, y la medida de 7,5 mm de la única laminita utilizada, que fue recuperada la cata estratigráfica. Además, en casi todas las piezas, exceptuando dos ejemplares, el formateado de las muescas, apenas ha conllevado una pequeña reducción de la anchura de los soportes laminares.

En cuanto al espesor, esta magnitud muestra bastante uniformidad en las piezas de las dos fases consecutivas mesolíticas. Así, tomando como referencia las láminas con muesca que presentan rastros de uso de Aizpea I y II, los valores medios apenas oscilan dos milímetros, 3,58 mm y 3,31 $\mathrm{mm}$ respectivamente.

Se puede concluir en relación a las dimensiones, que se eligieron soportes cortos y estrechos, formalizados con muescas para un uso directo. Estos módulos poco estilizados son comunes en la producción laminar de Aizpea, y han sido determinados por las mediocres condiciones de explotación del sílex del Flysch que se utilizó. Sin embargo, las piezas con huellas laborales son algo más anchas y, sobre todo, más espesas si se comparan con las medidas de las láminas brutas o las dimensiones medias de los geométricos, cuyo formateo exigió matrices más planas y estrechas (Cava, 2001: 139; Cava, 2005: 217).

Otro criterio complementario de selección de ciertas bases fue su sección sagital arqueada y con una curvatura distal (Fig. 3.4, 8, 12 y 14-16). Aunque este parámetro técnico es un reflejo de la influencia de la materia prima en la consecución de soportes, se optó por el empleo de estos elementos muy probablemente porque debieron ofrecer mejor comodidad de prensión con la mano durante los trabajos.

En las tres fases culturales de Aizpea, la mayoría de las muescas usadas son directas, y en los soportes laminares imperan las conformadas en el borde izquierdo (7, 4 de Aizpea I y 3 de Aizpea II), sobre el derecho (6, 3 recuperadas en Aizpea I, 2 en el horizonte II y 1 más en el III). Solamente se han empleado 3 piezas que disponían de muescas bilaterales (2 del tramo I y otra del II).

Las láminas denticuladas portadoras de estigmas microscópicos de utilización son 3: 1 completa fue haIlada en el tramo I y tiene retoque directo unilateral (Fig.

\begin{tabular}{|c|c|c|c|c|c|c|c|c|c|}
\hline \multirow{2}{*}{ FASE } & \multirow{2}{*}{ Analizados } & \multicolumn{5}{|c|}{ Usados } & \multirow{2}{*}{$\%$ Uso } & \multicolumn{2}{c|}{ Índices de identificación } \\
\cline { 3 - 6 } \cline { 5 - 6 } & & MD1 & MD2 & MD3 & MD4 & Total & & Cinemática & Mat. trabajada \\
\hline Aizpea I & 31 & 2 & 7 & 9 & 1 & 19 & 61,29 & $100 \%$ & $89,47 \%$ \\
\hline Aizpea II & 25 & - & 1 & 6 & 2 & 9 & 36 & $100 \%$ & $66,66 \%$ \\
\hline Aizpea III & 7 & 1 & - & 1 & - & 2 & 28,57 & $100 \%$ & $100 \%$ \\
\hline
\end{tabular}

Fig.4. Índices de uso y de determinación funcional. / Indexes of use and functional determination. 
3.19); en las otras dos, que provienen de la fase II, es bilateral, también directo, y en un caso marginal; además presentan curvatura sagital (Fig. 3.20 y 21). Las anchuras de cada una de estas piezas laminares son heterogéneas, varían entre 7, 11 y $14 \mathrm{~mm}$. Las medidas de longitud de las evidencias enteras alcanzan 32,5 $\mathrm{mm}$ y $45 \mathrm{~mm}$; en el tercer ejemplo, fragmentado, sobrepasa los $25 \mathrm{~mm}$. Y por lo que se refiere al espesor, oscila entre 3 y $5 \mathrm{~mm}$, siendo la media de 3,66 mm. Por tanto, presentan módulos dimensionales parecidos a los ejemplares con muesca.

\subsubsection{Lascas con muescas y piezas con denticulacio- nes sobre lascas y trozos irregulares}

Un reducido lote compuesto por 4 lascas con muesca ha sido también utilizado (Fig. 3.23-26). Se trata de soportes de muy pequeño formato, de sección aplanada y muescas unilaterales. El retoque es inverso en una de ellas, de la fase III; en el resto, directo a la derecha (1 de Aizpea I y 2 procedentes de la cata estratigráfica). A este grupo de elementos hay que añadir el único fragmento irregular de la unidad I, con huellas en una muesca directa a la izquierda (Fig. 3.22).

El conjunto de lascas denticuladas con rastros de uso lo integran 8 ejemplares. El tramo I reúne la mayor parte -7 (Fig. 3.27-33) - y el II aporta tan solo una pieza (Fig. 3.34). Los soportes son también pequeños, carentes de regularidad morfológica. El retoque que los configura es profundo y amplio, casi siempre continuo -solo en 2 ítems es parcial-, y en 3 casos, escaleriforme, conformando en estas piezas concretas frentes comparables a los de raederas. Según el número de bordes afectados y la dirección del mismo, en 5 objetos es unilateral directo, todos ellos de Aizpea I, 3 de sección aplanada, y 2 carenada (índice de espesor superior a 2; Fig. 3.31 y 32). El retoque bilateral se ha aplicado a 3 piezas, directo en 1 lasca de sección aplanada (Aizpea I; Fig. 3.30), y a otros dos soportes lascares de cierta tendencia carenoide (también con un índice de espesor igual o algo superior a 2), tanto directo (1 pieza de Aizpea I; Fig. 3.33) como inverso (1 del horizonte II; Fig. 3.34).

\subsection{Las zonas activas}

Las zonas activas son filos preparados mediante retoque, en su mayoría profundo, que, por un lado, ha generado muescas, algunas de las cuales a veces muestran una denticulación parcial. Por otro, un retoque escaleriforme se ha aplicado para la configuración de frentes denticulados. Cualesquiera de ellos han determinado las posibilidades de utilización de las zonas activas, dotándolas de una gran resistencia a los trabajos de fricción ejecutados.

La delineación de los bordes de las muescas es el rasgo de su fisonomía que mejor las define. Los contornos ligeramente cóncavos son los más numerosos, con independencia de los soportes donde se configuraron -lámina, laminilla, lasca laminar o lasca-, y aunque las fracturas postdeposicionales hayan truncado el desarrollo de las curvaturas originales. También se han registrado muescas con concavidades bien marcadas en 3 láminas (1 de Aizpea I y 2 de la fase II), en un fragmento irregular y en una lasca de sección aplanada del tramo I, y en otras 2 que aportó el sondeo estratigráfico. Sin embargo, no parece existir un patrón homogéneo que haya determinado la selección de los bordes denticulados de lascas. La mayor variabilidad se constata en el horizonte I, donde se han utilizado sobre todo filos sinuosos con denticulaciones poco acentuadas, que delinean siluetas rectilíneas o perfiles ligeramente cóncavos. Asimismo, se recurrió al uso, pero en menor medida, de bordes conformados por identaciones cóncavas individuales o dobles contiguas, bastante acentuadas.

A través de los objetivos del microscopio, los trazados de los bordes retocados describen líneas quebradas que combinan ondulaciones y zigzags. Estas irregularidades han repercutido en una localización diferencial de los micropulidos, más intensos y desarrollados en salientes o vértices.

Se han identificado 35 zonas activas en las 34 piezas denticuladas con huellas de uso, lo que significa que en la práctica totalidad se empleó un único borde. Hay una excepción, una lasca procedente de Aizpea I en la que se utilizaron los dos filos laterales denticulados (Fig. 3.33). Por otra parte, tampoco se explotaron las distintas potencialidades de uso de otras zonas activas de las que disponen algunas bases laminares, como filos naturales o retocados en los laterales contrarios $\mathrm{u}$ otras muescas contrapuestas en las partes mesiales.

En general, la longitud de los filos usados es pequeña -entre $5 \mathrm{~mm}$ y $11 \mathrm{~mm}$ - porque, o bien se utilizaron muescas de tamaño reducido, o bien de la largura disponible en el resto de los bordes dentados, solo se aprovechó una porción. En el caso de las muescas de mayor amplitud, la mitad inferior, y en los demás filos, la franja central. La limitada extensión de las superficies que se utilizaron debió permitir, por un lado, concentrar la fuerza que se aplicó a los gestos y, por otro, controlar la trayectoria de los útiles. De todo ello pueden inferirse varias características del uso: a) las limitadas áreas de intervención sobre las materias trabajadas con las que entraron en contacto; b) su elevado grado de dureza y c) la duración restringida de las actividades desarrolladas con estos tipos de bordes.

La adecuación de las zonas activas a las diferentes actividades reconstruidas se manifiesta también en el ángulo de los bordes elegidos para el uso. La variación de los mismos obedece, entre otras, a razones de eficiencia respecto a la resistencia que sin duda opusieron las materias rígidas que se transformaron a la presión de los bordes. El cotejo de los ángulos de filo con las materias trabajadas refleja diferencias significativas. Así, las piezas laminares con muescas o bordes 
denticulados, recuperadas en las tres fases de Aizpea, que actuaron sobre superficies óseas presentan ángulos más espesos, entre $58^{\circ}$ y $72^{\circ}$, que las que se utilizaron en el cepillado de madera, cuyos ángulos más frecuentes, hasta en el 69,23\% de los casos, se sitúan entre $40^{\circ}$ y $47^{\circ}$. Por otra parte, para el trabajo de la madera se llevó a cabo igualmente una elección selectiva de filos denticulados -frentes o muescas- de lascas con ángulos comprendidos entre $40^{\circ}-58^{\circ}$.

\subsection{Reconstrucción del uso: modos de acción y materias trabajadas}

El comportamiento cinemático de las piezas denticuladas con huellas de uso es bastante homogéneo. El diagnóstico funcional se ha basado en criterios interpretativos derivados del análisis de la extensión, posición e intensidad de micropulidos y embotamientos en las caras que forman las zonas activas. De la información obtenida se deduce que los movimientos reconstruidos corresponden a desplazamientos transversales que siguieron una dirección perpendicular a los filos activos y un sentido de trabajo único. Ha sido posible diferenciar dos tipos de acciones: cepillar y raspar.

En el desarrollo de las acciones de cepillado, el ángulo de contacto fue muy agudo, casi rasante. Las caras dorsales retocadas de los filos se mantuvieron delante durante los movimientos. Las opuestas, las caras ventrales, soportaron una fricción continua contra las materias trabajadas (Fig. 5.1). Por esta razón, es en ellas donde bandas estrechas de micropulidos cobran mayor intensidad y se concentran redondeamientos muy limitados (Fig. 6 y 7). Respecto a las caras dorsales, que en todos los casos examinados experimentaron un contacto menor, los micropulidos se circunscriben al arranque lateral de ciertas aristas de los negativos de los saltados del retoque.

En la práctica de acciones de raspado, los bordes se desplazaron con un ángulo de contacto de $90^{\circ}$, sien- do la cara ventral la conductora (Fig. 5.2). La ejecución de estos gestos, determinó que los micropulidos que se formaron se distribuyeran, de manera intermitente, en las mismas aristas activas, sin llegar a invadir las caras. Se localizan en finas bandas de extensión marginal y apariencia curvada, con estrías muy cortas, de fondo rugoso y orientación transversal (Fig. 8, a, b, c, f y g). También en partes protuberantes de la microtopografía del sílex, en forma de pequeñas manchas (Fig. 8, d y e).

Respecto al reconocimiento de las materias, en una primera aproximación se ha determinado su naturaleza rígida, asimilable a la de materiales duros orgánicos. A partir de los atributos cualitativos referidos a la apariencia visual de los micropulidos y del grado de embotamiento en los filos, se ha resuelto que las materias específicas transformadas han sido la madera y el hueso (Cf. Fig. 2). Hay, sin embargo, una pieza en la que el aspecto superficial poco definido de estos estigmas ha impedido precisar con fiabilidad el material concreto.

El trabajo de la madera se realizó exclusivamente mediante acciones de cepillado (Fig. 6 y 7). Predomina en el primer estadio de ocupación del yacimiento, así se refleja en la Figura 9, donde supone un $44,11 \%$. Y se llevó a cabo tanto con bordes dentados (53,33\%) como con muescas (46,66\%). En la fase posterior mesolítica, Aizpea II, experimenta un acusado retroceso -11,76\%-, hasta disminuir a una proporción mínima -2,94\%-en la etapa del Neolítico antiguo.

Las labores de raspado se destinaron al trabajo del hueso (Fig. 8), por medio de muescas, dos tercios de las mismas proceden de los horizontes mesolíticos I y II. En Aizpea II, también se utilizaron dos láminas con retoques denticulados. Su representación en cada uno de los contextos arqueológicos es baja, con una similar y muy discreta presencia porcentual -11,76\%-, en los mencionados horizontes I y II del Mesolítico geométrico, mientras que apenas alcanza un 2,94\% en el tramo más reciente, Aizpea III.
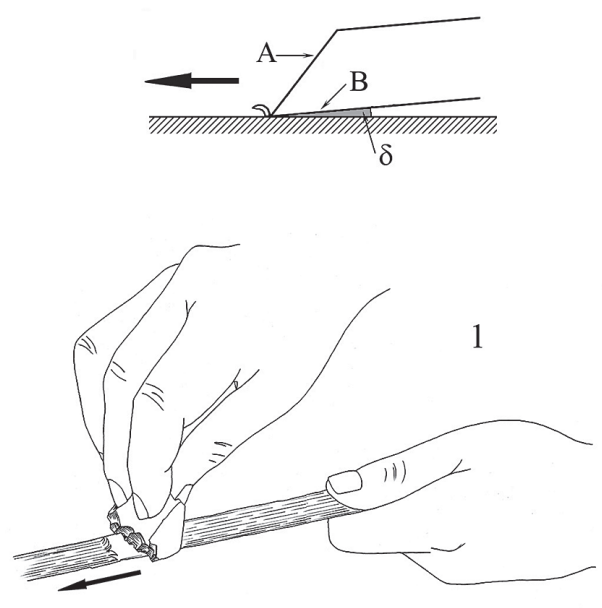

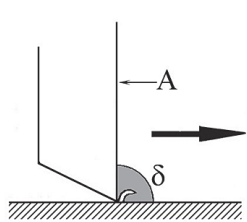

A: cara conductora

B: cara de mayor contacto

$\delta$ : ángulo de contacto

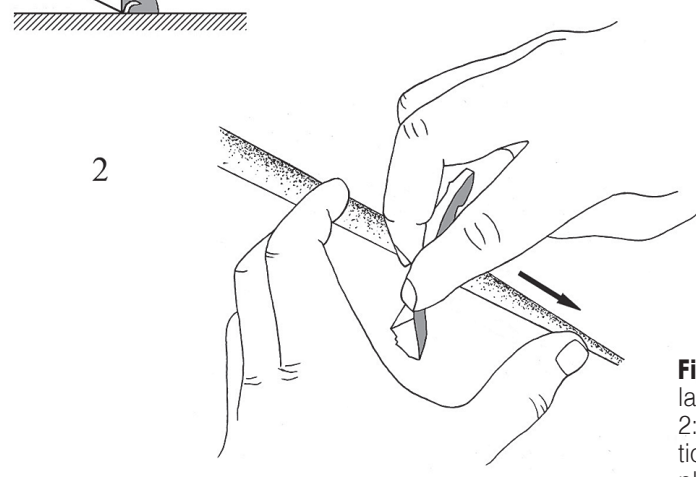

Fig.5. Reconstrucción de las acciones. 1: cepillar; 2: raspar. / Reconstruction of motions of use. 1 : planing; 2: scraping. 

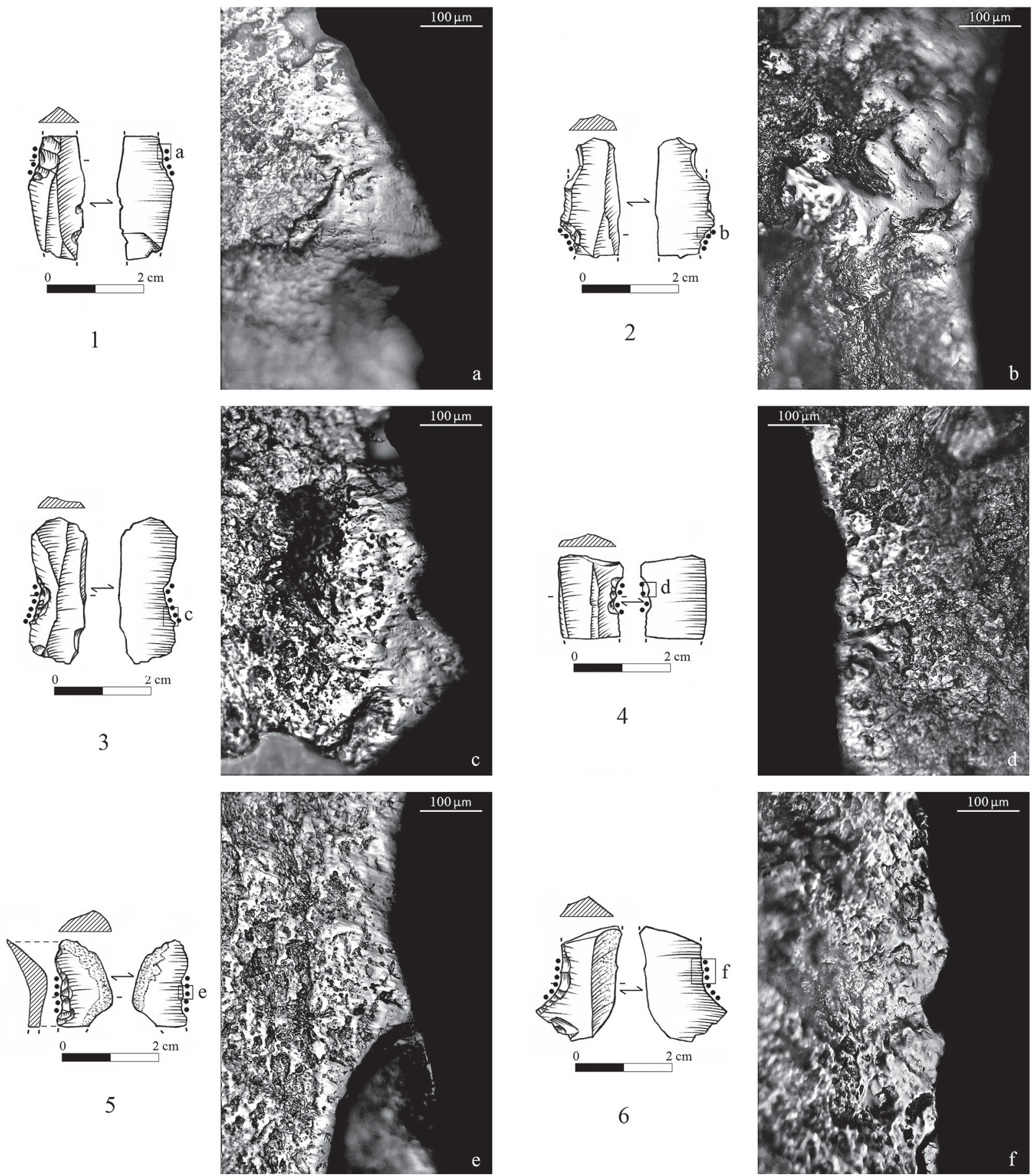

4
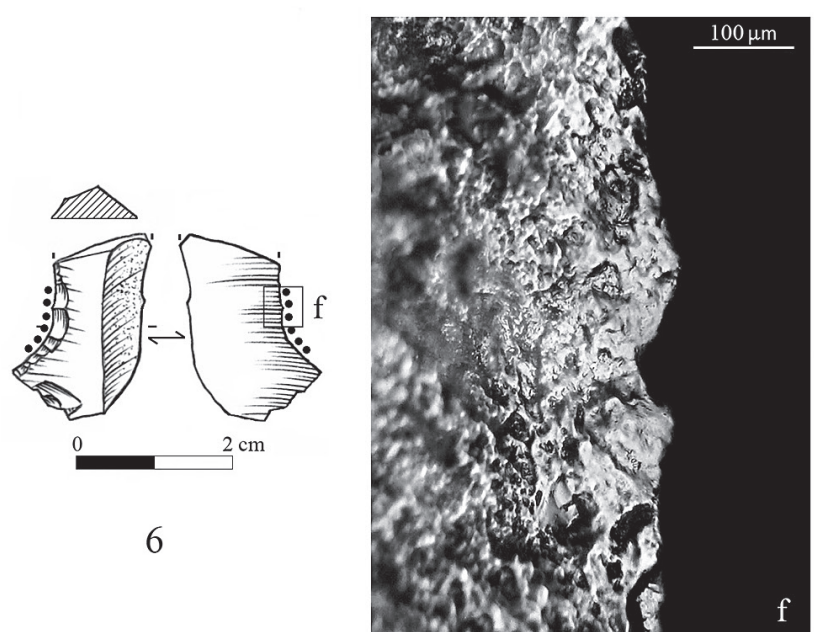

Fig.6. Láminas con muescas aisladas que se utilizaron para cepillar madera. Caras ventrales: micropulidos brillantes de topografía ondulada. Muestran diversos grados de regularización y tramado. Aizpea I: núm. 1-3; Aizpea II: núm. 4-6. Microfotografías a 200X. / Notched blades used to planing wood. Ventral faces: shining and ondulating developed micropolishes in various stages of linkage. Aizpea I: No. 1-3; Aizpea II: No. 4-6. Magnifications at 200X. 

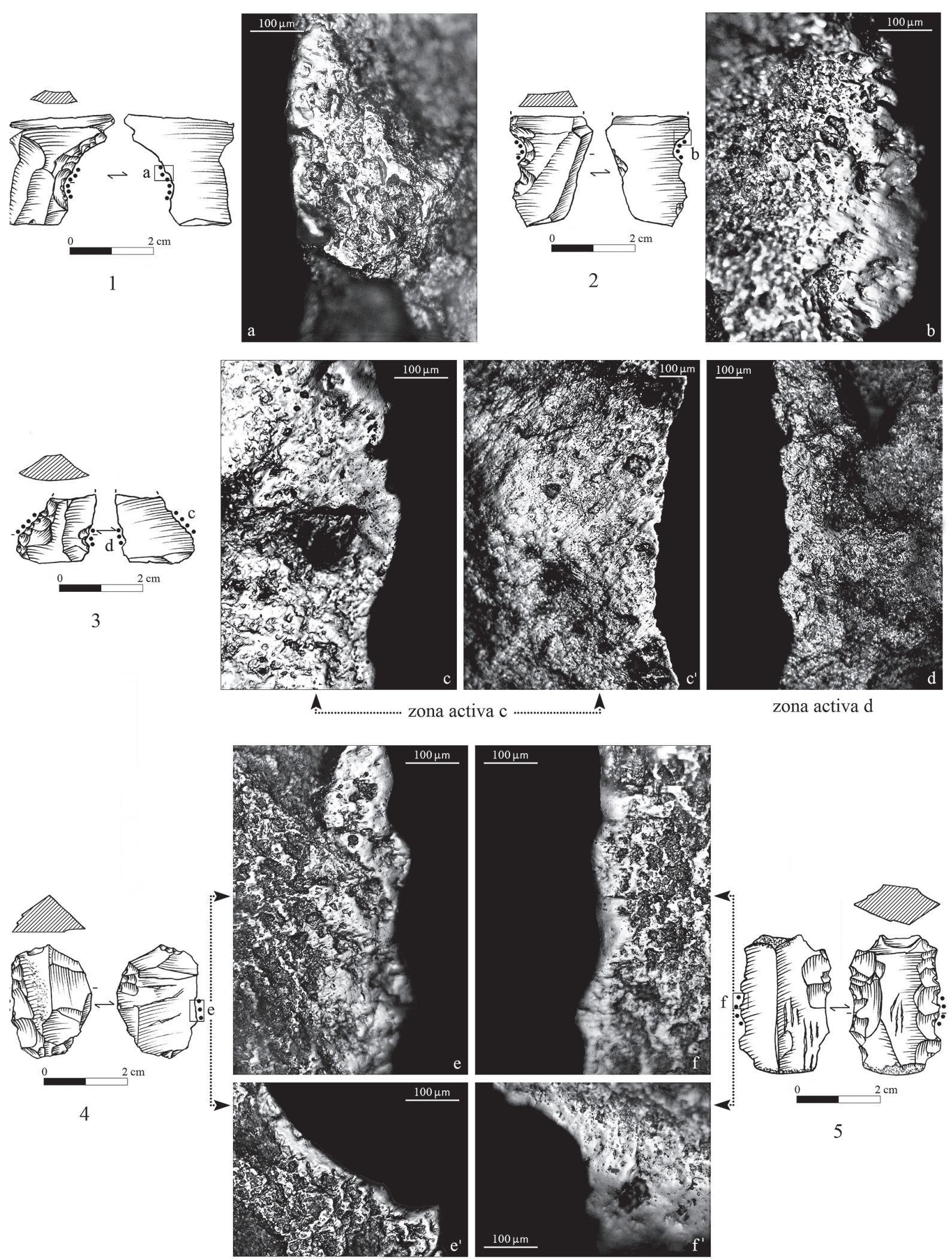

Fig.7. Piezas con muescas o filos denticulados sobre lascas carenadas o de sección aplanada usadas para cepillar madera. Bandas de micropulidos de topografía ondulada en los filos. Superficies pulidas con tramas intermedias de encadenamiento. Aizpea I: núm. 1-4; Aizpea Il: núm. 5. Microfotografías: todas a 200X, excepto c y d, a 100X. / Carinated or flattened section notched flakes or characterized by denticulates edges that were used to planing wood. Edge bands of ondulating micropolishes, with a middle degree of linkage of polished surfaces. Aizpea I: No. 1-4; Aizpea II: No. 5. All microphotographs at 200X, excepted $\mathrm{c}$ and $\mathrm{d}$ at $100 \mathrm{X}$ 

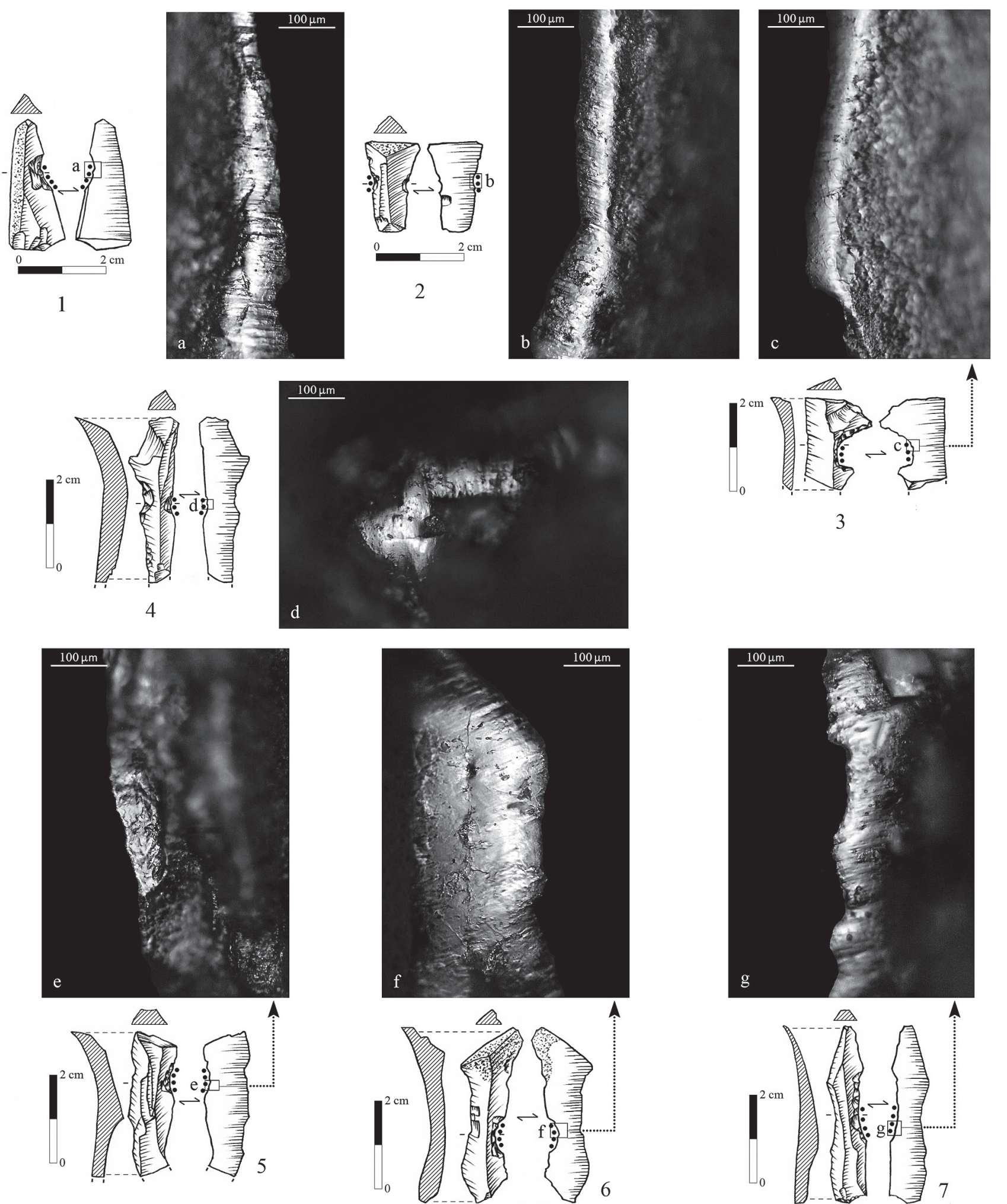

Fig.8. Huellas de raspado de hueso identificadas en muescas. Micropulidos brillantes y marginales que se localizan en zonas protuberantes de la topografía del sílex o forman biseles estrechos y convexos en las aristas de los filos. En algunos de ellos se aprecian estrías muy finas de orientación transversal. Aizpea I: núm 1-4: Aizpea II: núm. 5 y 6: Aizpea III: núm. 7. Microfotografías a 200X. / Micro-wears of bone scraping identified in notched blades. Shining marginal micropolishes in the higher points of the flint microtopography or forming a domed narrow bevels, restricted to the edges. On the surface of some of them, very thin striations running in the transversal working direction are visible. Aizpea I: No. 1-4; Aizpea II: No. 5 y 6; Aizpea III: No. 7 . Pictures taken at 200X. 


\begin{tabular}{|c|c|c|c|c|c|c|c|c|c|c|c|c|c|c|c|c|c|c|c|c|c|c|c|c|}
\hline \multirow{2}{*}{$\begin{array}{l}\text { Acción y } \\
\text { material }\end{array}$} & \multicolumn{6}{|c|}{ Aizpea I } & \multicolumn{6}{|c|}{ Aizpea II } & \multicolumn{6}{|c|}{ Aizpea III } & \multicolumn{6}{|c|}{ Cata } \\
\hline & MD1 & MD2 & MD3 & MD4 & $\#$ & $\%$ & MD1 & MD2 & MD3 & MD4 & $\#$ & $\%$ & MD1 & MD2 & MD3 & MD4 & $\#$ & $\%$ & MD1 & MD2 & MD3 & MD4 & $\#$ & $\%$ \\
\hline $\begin{array}{l}\text { Cepillar } \\
\text { madera }\end{array}$ & 2 & 7 & 5 & 1 & 15 & 44,11 & - & 1 & 3 & - & 4 & 11,76 & 1 & - & - & - & 1 & 2,94 & 2 & - & 1 & - & 3 & 8,82 \\
\hline $\begin{array}{l}\text { Raspar } \\
\text { hueso }\end{array}$ & - & - & 4 & - & 4 & 11,76 & - & - & 2 & 2 & 4 & 11,76 & - & - & 1 & - & 1 & 2,94 & - & - & 1 & - & 1 & 2,94 \\
\hline $\begin{array}{c}\text { Cepillar } \\
\text { mat. indet. }\end{array}$ & - & - & - & - & - & - & - & - & 1 & - & 1 & 2,94 & - & - & - & - & - & - & - & - & - & - & - & - \\
\hline
\end{tabular}

Fig.9. Cruce de acciones practicadas y materias trabajadas por fases. / Data crossing by phases about the type of movement performed and worked materials.

\subsection{La intensidad de uso}

El estudio traceológico ha demostrado que los útiles denticulados con estigmas laborales, al margen del segmento cronocultural de procedencia, no fueron aprovechados con intensidad ni tuvieron un uso prolongado. La práctica totalidad de los elementos examinados, más allá de la variedad morfológica que representan, conservan una sola zona con huellas de utilización, muescas o frentes denticulados. Ello refleja un desinterés por explotar otras partes complementarias, potencialmente útiles y disponibles en los instrumentos, como los filos laterales brutos o retocados $u$ otras muescas contrapuestas. Solamente se ha constatado el empleo para cepillar madera de un denticulado bilateral en una misma pieza, una lasca de Aizpea I.

Hay otros indicios que denotan que los diferentes conjuntos usados participaron en tareas concretas que se acometieron en poco tiempo y, además, no requirieron una utilización intensiva de estos útiles. Se trata del estadio medio de desarrollo en que se hallan los rasgos característicos que definen las superficies de los micropulidos identificados y su reducida extensión en las caras de los filos activos.

Por otra parte, y con independencia del contexto arqueológico, en ningún caso las piezas fueron reutilizadas y tampoco se sometieron a un mantenimiento técnico para dilatar su vida útil mediante la práctica de reavivados. En consecuencia, los retoques escamosos que configuran los bordes de algunas de las lascas usadas fueron intencionales y se obtuvieron por percusión directa.

Aunque la fricción ocasionó un ligero desgaste y embotamiento de ciertos bordes, en la mayoría de ellos, los ángulos de filo permanecieron intactos, exentos de la necesidad de ser reparados. En realidad, los cortos lapsos de uso, durante los cuales las piezas denticuladas funcionaron como utensilios, actuaron como un factor determinante en la perduración de la eficacia de los filos. Tanto así que se desecharon después del uso, aun cuando las zonas activas todavía estaban operativas y su utilidad no había sido agotada.

\section{LA INTERVENCIÓN DE LAS PIEZAS DENTI- CULADAS EN LOS PROCESOS TÉCNICOS DEL TRABAJO DE LA MADERA Y DEL HUESO}

En relación con los trabajos de madera identificados, se han vinculado con el aprovechamiento industrial de esta materia prima para la fabricación de objetos y útiles. La madera era fácil de aprovisionar en las zonas boscosas que rodearon al refugio, según se desprende de la evolución del paisaje vegetal reconstruido a partir del registro paleobotánico (Zapata, 2001). Y dispusieron de ella, habida cuenta de su empleo selectivo como combustible en los distintos episodios de habitación de Aizpea.

El conocimiento de las cualidades físicas y de las propiedades mecánicas de las potenciales especies arbóreas o arbustivas a su alcance, es decir, su dureza y resistencia, su naturaleza impermeable o imputrescible o su facilidad para ser trabajadas, debieron ofrecer un amplio abanico de posibilidades de utilización.

Cualquier tentativa de interpretación acerca de la finalidad de las acciones de cepillado, y a la postre, de la función de las piezas denticuladas utilizadas de este modo, requiere insertarlas en la cadena técnica de transformación de la madera, que varía según el tipo de artefacto y su destino funcional (Laborda, 2010). Si bien no se ha conservado ningún vestigio que aporte información de esta naturaleza, es posible que intervinieran mediante actuaciones específicas -regularizar o igualar zonas determinadas de la morfología o el contorno y/o de partes operativas- durante la conformación de utensilios u objetos. De la misma manera, pudieron utilizarse en los últimos pasos del proceso de manufactura, para lograr un acabado liso y parejo de las superficies. En el caso de las muescas, la morfología de los filos activos y los estigmas de uso sugieren que los cepillados se aplicaron a soportes estrechos y, en algunos casos, convexos, por ejemplo, varillas, ramas de pequeño calibre o incluso astillas. Por el contrario, en los bordes dentados de lascas y láminas, la relativamente mayor extensión de las áreas donde se concentran las huellas microscópicas indica la fricción contra superficies de madera algo más amplias.

A falta de evidencias directas, ha de suponerse la posible elaboración de un repertorio de productos de madera destinados a diferentes usos como mangos, empuñaduras, palos para extraer raíces, tubérculos o para cavar, contenedores, etc. Por otra parte, durante la secuencia de estancias temporales en el Mesoneolítico se desarrollaron actividades venatorias indispensables para garantizar una de sus bases alimentarias. Para la caza de un variado espectro de ungulados, cada grupo prehistórico dispuso de un equipamiento cinegético. La 
evolución en el diseño de los tipos de armaduras microlíticas ha quedado reflejada en las distintas fases culturales (Cava, 2001). Y es en el ciclo del proceso productivo de instrumentos de caza donde el uso de muescas y piezas con frentes denticulados también pudo materializarse. Es posible que interviniesen en la manufactura de fustes de armas arrojadizas que dotaron con azagayas, piezas éstas últimas de las que se recuperaron cuatro pequeños fragmentos entre la industria ósea de los tres tramos del depósito. Igualmente, en la confección de vástagos de flecha, en los cuales insertaron microlitos. Así lo confirma el uso como proyectiles de geométricos trapeciales y de morfología triangular (Domingo, 2005). Pero también debieron utilizarse con similar función, todavía sin contrastar, puntas y laminitas de dorso, que junto a las armaduras anteriores constituyen la base instrumental mayoritaria de la industria lítica retocada.

Tampoco hay que descartar la participación de alguno de los elementos denticulados con estigmas de uso en el proceso de elaboración de otros hipotéticos modelos, también en material leñoso, quizás desprovistos de armaduras, esto es, astiles y/o varas simplemente aguzados, a modo de jabalinas o dardos, que pudieron complementar las panoplias de caza.

Otro aspecto que merece ser comentado es la posibilidad de que los utillajes denticulados hubieran estado involucrados en labores de remodelación o reparación de daños o deterioros en efectos, bien fabricados en el abrigo, bien que habrían traído consigo las gentes que se establecieron en Aizpea. El objetivo hubiera sido dilatar sus vidas útiles porque todavía eran aprovechables. Sin embargo, no se debe olvidar que las hipotéticas operaciones de cepillado realizadas debieron ser limitadas y orientadas a modificar zonas muy concretas de las superficies.

Aunque menos abundantes, las labores sobre hueso podrían asociarse a las actividades de carácter industrial en materias óseas -hueso y asta- que llevaron a cabo quienes ocuparon Aizpea en diferentes estadías entre el final del Mesolítico y el Neolítico antiguo. En el registro arqueológico se han documentado residuos del trabajo técnico y trazas de manipulación en dichos materiales. Además, se ha propuesto que una parte del instrumental se hubiera elaborado en el sitio, a partir de los desechos esqueléticos del procesado y consumo de los animales cazados (Barandiarán, 2001).

La ejecución de los trabajos constatados en el estudio traceológico se podría justificar en el marco de la producción de algunos de los utensilios de pesca -anzuelos rectos de diferente formato, procedentes de los tramos inferior y medio del Mesolítico; también de ciertas armas de caza -los fragmentos de azagayas mencionados con anterioridad- $u$ otros artefactos de uso doméstico recuperados como punzones, puntas planas, espátulas o alisadores.

Sin duda, los imperativos funcionales determinaron los diferentes esquemas operativos de su confección.
La práctica del raspado por medio de láminas con muesca o denticuladas fue un procedimiento de trabajo que pudo llevarse a cabo en el estadio preliminar de su elaboración con el fin de eliminar estigmas técnicos. También en el intermedio, para regularizar superficies, tal como se colige, por ejemplo, de las trazas macroscópicas conservadas en un biapuntado de Aizpea I (Barandiarán, 2001: 185), y en la fase de acabado. Esta acción técnica pudo aplicarse asimismo al arreglo superficial de desperfectos o a someras reparaciones de partes específicas de objetos o herramientas deterioradas durante el uso o debido a causas accidentales.

\section{LA CONTEXTUALIZACIÓN DE LOS RESUL- TADOS}

Hasta el día de hoy, son escasos los estudios realizados con la metodología del análisis traceológico, aplicada a conjuntos de piezas denticuladas recuperadas en diferentes contextos mesolíticos de la Península ibérica. Informaciones sobre el uso de estos artefactos para raspar y cepillar materias de naturaleza rígida -madera, hueso y asta- se remontan a horizontes datados en la segunda mitad del noveno milenio BP y proceden de yacimientos localizados en diferentes entornos. Así ocurre con la muestra de lascas denticuladas y raederas utilizadas en el nivel Ib (Laborda, 2010), breve episodio de habitación en la cercana cueva prepirenaica de Zatoya, adscrito a un genérico Mesolítico de ascendencia laminar; y en el exiguo lote de muescas con estigmas laborales producidos por el trabajo de materias óseas, del nivel II de Roc de Migdia, refugio estacional localizado en el occidente mediterráneo catalán (Rodríguez, 1993).

En los últimos años, se han comenzado a conocer interpretaciones sobre los diversos usos de elementos denticulados que forman parte de los equipamientos líticos atribuidos a las distintas fases que articulan el Mesolítico pleno y avanzado del Valle del Ebro. Las referencias funcionales son el resultado de los análisis de piezas de las que se sirvieron grupos de cazadores-recolectores que se instalaron de manera temporal en establecimientos próximos a Aizpea o situados en el espacio geográfico de la parte alta de la cuenca del Ebro. Del abrigo de Artusia, ubicado en la vertiente meridional de la Sierra de Alaiz (Navarra), interesan las láminas y lascas retocadas con muescas o filos denticulados que entregaron los niveles de la secuencia mesolítica del yacimiento, Artusia III-V. Las zonas activas identificadas, en varios ejemplares más de una, se destinaron al raspado de piel seca, hueso y madera (García Martínez de Lagrán et al., 2014; Mazzuco et al., 2016). En el abrigo treviñés de Mendandia, el nivel III -Mesolítico geométrico- y, especialmente el horizonte IV, que contiene una densa ocupación con industrias de la facies de denticulados, evidencian el empleo de algunas láminas, pero, sobre todo, numerosas lascas retocadas con denticulaciones y muescas, como instrumental dedicado a actividades relacionadas con el 
procesado y transformación de materias orgánicas duras (Mazo, 2005; Mazzuco et al., 2016). Por su parte, las piezas denticuladas procuradas en la excavación de los niveles IV y IIIb2, adscritos a dos fases del Mesolítico geométrico del depósito del abrigo de Atxoste, fueron utilizadas en las fases de fabricación y/o mantenimiento de objetos o útiles elaborados en materiales de origen animal (piel en estado seco, y, en menor medida, hueso o asta) y vegetal (madera) (Perales et al., 2016; Mazzuco et al., 2016).

El empleo de este tipo de utensilios se ha rastreado también en otros yacimientos mesolíticos, alejados geográficamente de Aizpea. Un ejemplo lo integra la reducida colección, compuesta por soportes laminares con muescas que conservaban huellas, procedente del abrigo de Valmayor XI, localizado en el sector oriental de la cuenca del Ebro. Las piezas se han asociado a tareas de tratamiento de la piel y al trabajo de materias duras indeterminadas (Mazzuco et al., 2016). Asimismo, se ha constatado el comportamiento funcional de estos elementos industriales en enclaves del área levantina, zona que cuenta una más larga tradición en el estudio de unidades geométricas, puesto que hace más de cuarenta años que J. Fortea (1973) individualizó varias de estas facies como complejos tecnológicos. Dentro de este ámbito de la franja mediterránea, los niveles mesolíticos de la cueva de Cocina o la fase A del yacimiento al aire libre de Benàmer (Alicante) ejemplifican que a pesar del interés que se concede en el Mesolítico reciente a la formalización de armaduras geométricas microlíticas, el desbaste laminar se practica también para la manufactura y uso de láminas con una sola o múltiples muescas. Los análisis de trazas microscópicas de uso demuestran una gran homogeneidad cinemática, por su aplicación en acciones de raspado en una gama de materiales, principalmente restringida a aquellos de mayor dureza como hueso y madera. Aunque también se han identificado algunos indicios del trabajo sobre materias vegetales blandas (Mazzuco et al., 2016; Rodríguez, 2011; Jover et al., 2012). En el yacimiento de El Collado (Valencia), similares actuaciones sobre estas mismas resistentes materias orgánicas se llevaron a cabo, de forma preferente, con lascas dotadas de muescas, la mayoría perteneciente al nivel II, que se incardina en el horizonte de muescas y denticulados del Mesolítico regional (Gibaja et al., 2018).

Fuera de la península ibérica, se han buscado también paralelos funcionales, asimilables a los usos propuestos en Aizpea, en piezas denticuladas que utilizaron comunidades mesolíticas de Europa occidental. Aunque la escasez de efectivos con rastros laborales facilita poco margen para establecer comparaciones, al menos permite vislumbrar tendencias generales. La primera es el empleo esporádico de muescas y denticulados en trabajos sobre madera, hueso (Crombé y Beugnier, 2013), y en tareas relacionadas con el consumo cárnico, documentado en niveles encuadrables en el Mesolítico sauveterriense, como los definidos en el abrigo de Vionnaz (Suiza) y en el sector I del campamento de Mondeval de Sora 1, ubicado en la región italiana del Véneto (Pignat y Plisson, 2000; Fontana et al., 2009). Tales limitados y testimoniales usos son característicos igualmente en la evolución industrial de las fases antigua y final del Mesolítico, en enclaves del pirineo andorrano, y en la dinámica del equipamiento lítico ente el Sauveterriense y el estadio más reciente Castelnoviense en yacimientos del valle del Ródano. Las referencias concretas disponibles son unos pocos ejemplares registrados en los niveles 5 y 6 del abrigo de Balma Margineda (Philibert, 2002) y en las dos principales ocupaciones del campamento de Mourre de Sève (De Stefanis et al., 2016).

La segunda tendencia se concluye de los resultados traceológicos obtenidos del estudio de algo más de un centenar de láminas y laminitas con muescas que proceden de horizontes del Mesolítico, datados en el VII - VI milenio cal BC, y reconocidos en una decena de estaciones de Francia y Bélgica. En estos análisis se subraya la importancia de las labores de raspado con estas piezas, enmarcadas en las etapas iniciales del procesado de fibras o plantas no leñosas de naturaleza silícea, probablemente destinadas a elaboraciones de cestería (redes, recipientes, contenedores, entre otros) y cordelería (para fabricar hilos y cuerdas). Otras utilizaciones complementarias al aprovechamiento de recursos vegetales específicos se concretan en cometidos menos frecuentes de acabado de objetos en madera y hueso, vinculados a la elaboración de útiles de caza -astiles de flechas- o ingenios de pesca (Gassin et al., 2013; Gassin et al., 2014).

También se han publicado informaciones sobre la función de un reducido conjunto de denticulados y muescas del espléndido yacimiento maglemosiense de Star Carr. Los estigmas microscópicos identificados son el reflejo del trabajo de la madera, que se desarrolló con cuatro elementos localizados en un área de talla de hachas. Igualmente se utilizaron sobre hueso o en relación con labores de carnicería (Dumond, 1988; Conneller et al., 2018).

Respecto a las dos únicas piezas de Aizpea III, una lámina y una lasca con muesca, que presentaban huellas laborales, carecen de valor representativo, en concordancia con la drástica reducción de efectivos denticulados en esta fase datada en el Neolítico antiguo. No permiten, por tanto, extraer la menor conclusión de orden funcional. Solamente sugieren, por un lado, que este tipo de útiles continúan vigentes durante dicha ocupación, pero con una mínima frecuencia de formateado e utilización. Por otro, indican la perduración de modos de uso similares a los reconstruidos en piezas de las etapas precedentes mesolíticas. Trazas diagnósticas funcionales del trabajo de madera y/o hueso se han identificado en muescas y denticulados de otros horizontes de este mismo período como el nivel I de Zatoya (Laborda, 2010) y los niveles II y IIIb1 del abrigo de Atxoste (Perales et al., 2014). 


\section{CONCLUSIONES}

A través del análisis traceológico se ha podido reconstruir e interpretar el uso directo de una muestra de denticulados. Fueron utilizados como utensilios de trabajo para desarrollar, en el propio lugar de hábitat, actividades ajustadas a las necesidades del momento, y destinadas a fabricar o reponer instrumentos, armas o accesorios en madera y hueso, y/o arreglar útiles u objetos ya elaborados en estas materias. Aunque en el registro arqueológico hay evidencias de la explotación de recursos de origen animal, así lo confirma la colección de piezas óseas transformadas en utensilios de diferente asignación funcional y armas, de la existencia de probables artefactos en madera solamente hay indicios indirectos derivados del estudio de huellas laborales.

Las variantes formales que muestran estas herramientas respecto a los diversos soportes en los que se conformaron, si bien con un dominio de los laminares; la escasa regularidad morfológica, el pequeño tamaño de las piezas (en todos los casos de reducida longitud) o la presencia de ejemplares de tendencia carenoide, ha de relacionarse con los contextos de producción y las limitaciones para el desbaste que presentaba el sílex del Flysch utilizado. El pragmatismo aplicado en las técnicas de producción no reparó ni en la selección exigente de los soportes, ni tampoco en términos de calidad de factura. Sin embargo, la consecución deliberada de otros parámetros como zonas activas resistentes, retocadas con muescas y/o denticulaciones, en algunos casos mediante retoques escaleriformes, incluso con disposiciones inversas, o los ángulos de los filos, entre $40^{\circ}-72^{\circ}$, obedecieron a los requerimientos operativos que debieron exigir las labores de raspado y cepillado de materias duras orgánicas inferidas.

La demanda de piezas denticuladas estuvo asociada a empleos expeditivos. Además, ninguna de ellas fue objeto de intervenciones técnicas de mantenimiento hasta su abandono. Una vez cumplido su cometido, se desecharon sin haberse maximizado su rendimiento y sin agotar su potencialidad de uso. Estos útiles se fabricaron ad hoc, con el fin de atender objetivos o satisfacer necesidades inmediatas de los sucesivos habitantes. Los trabajos se inscriben dentro de actividades de transformación de materias primas perecederas de origen vegetal y son también una muestra del aprovechamiento de recursos animales, en concreto, de las carcasas y otras piezas óseas de presas abatidas. Se suman a otros de carácter técnico/industrial -talla lítica y fabricación de utillaje óseo- y a las actividades inherentes a la subsistencia, en relación con la explotación integral del medio circundante, que practicaron los diferentes grupos que se refugiaron durante estancias temporales en el abrigo de Aizpea.

Se ha apreciado también la pervivencia del interés en la fabricación y uso de este tipo de herramientas, con un máximo destacado en la fase antigua del Mesolítico geométrico. En la etapa más reciente de este período disminuye de manera acusada, para convertirse en actividad residual en el horizonte atribuido al Neolítico antiguo.

Al igual que se demostró en el estudio de los equipamientos de armaduras geométricas, los denticulados, cuyo uso se ha determinado en este trabajo, también tienen un significado funcional propio. Pero los resultados obtenidos deberían ser complementados con el análisis traceológico tanto del restante instrumental retocado como de los productos brutos. Pues la aplicación de esta metodología analítica ofrece una perspectiva que permitiría aproximarse a la diversidad de actividades llevadas a cabo en las distintas ocupaciones, y comprender su significado en las estrategias de subsistencia de los grupos de cazadores-recolectores que reiteraron el asentamiento en Aizpea desde inicios del VIII milenio hasta mediado el VII milenio BP.

\section{AGRADECIMIENTOS}

Quiero dejar constancia de mi gratitud al Dr. Jesús Sesma, Técnico Arqueólogo de la Sección de Arqueología del Servicio de Patrimonio Histórico del Gobierno de Navarra, por facilitarme el acceso y el estudio directo de los materiales.

\section{BIBLIOGRAFÍA}

Alday, A., 2002. Las unidades industriales mesolíticas en la alta y media cuenca del Ebro. Complutum 13, 19-50.

Alday, A., Cava, A., 2009. El Mesolítico geométrico en Vasconia. In: Utrilla, P., Montes, L. (eds.), El mesolítico geométrico en la Península Ibérica. Monografías Arqueológicas. Prehistoria $44,93-129$.

Alday, A., Castaños, P., Perales, U., 2012. Quand ils ne vivaient pas seulement de la chasse: preuves de domestication ancienne dans les gisements néolithiques d'Atxoste et de Mendandia (Pays Basque). L'Anthropologie 116(2), 127-147.

Barandiarán, I., 2001. La industria ósea: elaboraciones sobre hueso, asta y concha. En: Barandiarán, I., Cava, A. (dirs.), Cazadores y recolectores en el Pirineo navarro. El sitio de Aizpea entre el 8.000 y 6.000 años antes de ahora, 179-212. Anejos de Veleia, Series Maior 10.

Bustos, G., Baena, J., 2016. Preliminary experimental insights into differential heat impact among lithic artifacts. Journal of Lithic Studies 3(2). https://doi.org/10.2218/jls.v3i2.1396.

Cahen, D., Gysels, J., 1983. Techniques et fonctions dans I'industrie lithique du groupe de Blicquy (Belgique). In: Cauvin, M. C. (dir.), Traces d'utilisation sur les outils néolithiques du Proche Orient, Travaux de la Maison de l'Orient 5, 37-52.

Caspar, J.P., Philippe, F., Emmanuelle, M., 2005. Identification et reconstitution des traces de teillaje des fibres végétales au Néolithique. Bulletin de la Société Préhistorique Française 102(4), 867-880.

Cava, A., 1994. El Mesolítico en la Cuenca del Ebro. Un estado de la cuestión. Zephyrus XLVII, 65-91.

Cava, A., 1997. L'abri d'Aizpea. Un facies à trapèzes et son évolution à la fin du Mésolithique sur le versant sud des Pyrénées. Préhistoire Européenne 10, 151-171. 
Cava, A., 2001. La industria lítica. In: Barandiarán, I., Cava, A. (dirs.), Cazadores-recolectores en el Pirineo navarro. El sitio de Aizpea entre 8.000 y 6.000 años antes de ahora. Anejos de Veleia, Series Maior 10, 63-147.

Cava, A., 2005. Las industrias líticas retocadas de Mendandia. En: Alday, A. (dir.), El campamento prehistórico de Mendandia: Ocupaciones mesolíticas y neolíticas entre el 8500 y el 6400 B. P., 139-235. Diputación Foral de Álava, Vitoria.

Clemente, I., 1997. Thermal alterations of Flint implements and the conservation of microwear polish: preliminary experimental observations. In: Ramos, A., Bustillo, M.A. (eds.), Siliceous rocks and culture, 525-535. Universidad de Granada, Granada.

Conneller, C., Little, A., García Díaz, V., Croft, S., 2018. The worked flint. In: Milner, N., Conneller, C., Taylor, B. (eds.), Star Carr. Volume 2: studies in technology, subsistence and environment, 493-534. White Rose University Press, York.

Crombé, P., Beugnier, V., 2013. La fonction des industries en sílex et les modalités d'ocupation des territoires au Mésolithique. Le cas de zones sableuses du nord-ouest de la Belgique et les Pays-Bas (8700-5400 cal. BC). L'Anthropologie 117(2), 172-194.

De Stefanis, C., Beyries, S., Binder, D., 2016. Use wear analysis of a Mesolithic assemblage: the Mourre de Sève rock shelter (Sorgues-Vaucluse). Preistoria Alpina, 48, 139-150.

Domingo, R., 2005. Análisis functional de los microlitos geométricos del abrigo de Aizpea (Arive, Navarra). Veleia 22, 27-49.

Domingo, R., 2009. Caracterización funcional de los microlitos geométricos: el caso del valle del Ebro. In: Utrilla, P., Montes, L. (eds.), El mesolítico geométrico en la Península Ibérica. Monografías Arqueológicas. Prehistoria 44, 375-389.

Dumont, J.V., 1988. A microwear análisis of selected artefacts types from the Mesolithic sites of Star Carr and Mount Sandel. BAR British Series 187, Archaeopress, Oxford.

Fontana, F., Govoni, L., Guerreschi, A., Padoanello, S., Siviero, A., Thun Hohenstein, U., Ziggioti, S, 2009. L'occupazione sauveterriana di Mondeval de Sora 1, settore I (San Vito di Cadore, Belluno) in bilico tra accampamento residenziale e campo da caccia. Preistoria Alpina 44, 205-225

Fortea, J., 1973. Los complejos microlaminares y geométricos del Epipaleolítico mediterráneo español, Memorias del Seminario de Prehistoria y Arqueología. Universidad de Salamanca., Salamanca.

García Martínez de Lagrán, I., Rojo, M.A., Iriarte, E., García Gazólaz, J., Tejedor, C., Gibaja, J. F., Moreno, M., Pérez Jordà, G., Ruiz Alonso, M., Sesma, J., Garrido, R., Carrancho, A., Peña, L., 2014. Paleoambiente y cambios culturales en los inicios del Holoceno: el abrigo de Artusia (Unzué, Navarra). Trabajos de Arqueología Navarra 26, 7-98.

Gassin, B., Marchand, G., Claud, E., Guéret, C., Philibert. S., 2013. Les lames à coches du second Mésolithique: des outils dédiés au travail des plantes? Bulletin de la Société Préhistorique Française 110(1), 25-46.

Gassin, B., Gibaja, J.F. Allard, P., Boucherat, T., Claud, E., Clemente, I., Gueret, C., Jacquier, J., Khedhaier, R., Marchand, G., Mazzucco, N., Palomo, A., Perales, U., Perrin, T., Philibert, S., Rodríguez, A., Torchy, L., 2014. Late Mesolithic notched blades from western Europe and North Africa. Technological and functional variability. In: Marreiros, J., Bicho, N., Gibaja, J.F. (eds.), International conference on use-wear analysis. Use-wear 2012, 224-231. Cambridge Scholars Publishing, Newcastle upon Tyne.
Gibaja, J.F., Morell, B., Terradas, X., 2018. Approaching subsistance activities in the Mesolithic by means of lithic tools: the case of El Collado site (Oliva, Eastern Iberia). Journal of Archaeological Science, Reports 18, 1026-1035.

González Urquijo, J.E., Ibáñez Estévez, J.J., 1994. Metodología de análisis funcional de instrumentos tallados en sílex. Cuadernos de Arqueología 14, Universidad de Deusto, Bilbao.

Jover, F.J., Rodríguez Rodríguez, A.C., Molina, F. J., 2012. Obtención, producción y uso de rocas silíceas en el Mesolítico geométrico, fase $\mathrm{A}$, de la fachada oriental de la Península Ibérica: el yacimiento de Benàmer (Muro, Alicante). Munibe Antropologia-Arkeologia 63, 105-135.

Laborda, M.A, 2010. Análisis de huellas de uso. Su aplicación al estudio de la funcionalidad del instrumental lítico de la cueva de Zatoya (Navarra). Tesis Doctoral. Universidad de Navarra. Disponible en: https://dadun.unav.edu/handle/10171/19863.

Martí, B., Aura, J.E., Juan, J., García Puchol, O., Fernández López de Pablo, J., 2009. El Mesolítico geométrico de tipo "Cocina" en el País Valenciano. In: Utrilla, P., Montes, L. (eds.), El mesolítico geométrico en la Península Ibérica. Monografías Arqueológicas. Prehistoria 44, 205-258.

Mazo, C., 2005. Análisis de huellas de uso de la serie lítica retocada del nivel IV de Mendandia. En: Alday, A. (dir.), El campamento prehistórico de Mendandia: Ocupaciones mesolíticas y neolíticas entre el 8500 y el 6400 B. P., 285-319. Diputación Foral de Álava, Vitoria.

Mazzucco, N., Gibaja, J. F., Perales, U., San Millán, M., García Puchol, O., Rojo, M., Royo, J. I., García Martínez de Lagrán, I., Juan, J., García Gazólaz J., Gassin, B., 2016. Insights into the Late Mesolithic toolkit: use-wear analysis of the notched blades. Case-studies from the Iberian Peninsula. Preistoria Alpina 48, 151-157.

Perales, U., Ibáñez Estévez, J. J., Alday, A., 2014. The use of flint artifacts from Early Neolithic levels at Atxoste (Basque Country). An interpretation of site function through use-wear analyses. In: Marreiros, J., Bicho, N., Gibaja, J.F. (eds.), International conference on use-wear analysis, Use-wear 2012, 59260. Cambridge Scholars Publishing, Newcastle upon Tyne.

Perales, V., Soto, A., Alday, A., 2016. El análisis tecno-funcional y la gestión de la industria lítica del nivel IIlb2 de Atxoste (Álava, España). Munibe Antropologia-Arkeologia 67, 313-323.

Philibert, S., 2002. Les derniers «sauvages». Territoires économiques et système techno-fonctionnels mésolitiques. BAR International Series 1069, Archaeopress, Oxford.

Philibert, S., Briois, F., Manen, C., 2014. Use-wear analysis of early Neolithic lithic industry of Peiro Signado: A pionner implantation in south of France. In: Marreiros, J., Bicho, N., Gibaja, J. F. (eds.), International Conference on use-wear analysis. Use-wear 2012, 642-651. Cambridge Scholars Publishing, Newcastle upon Tyne.

Pignat, G., Plisson, H., 2000. Le quartz, pour quell usage? L'outillage mésolithique de Vionnaz (Suisse) et l'apport de la tracéologie. In: Crotti, P. (ed.), MESO 97. Actes de la table ronde Épipaléolithique et Mésolithique, 65-78. Cahiers d'archéologie romande 81.

Plisson, H., 1985. Étude fonctionnelle d'outillages lithiques préhistoriques par l'analyse des micro-usures: recherche méthodologique et archéologique, Thèse de Doctorat. Université de Paris I, Paris. 
Rodríguez Rodríguez, A. C., 1993. L'analyse fonctionnelle de l'industrie lithique du gisement Épipaléolithique/Mésolithique d'el Roc de Migdia (Catalogne - Espagne). Resultats preliminaires. Prèhistoire Européenne 4, 63-84.

Rodríguez Rodríguez, A.C., 2011. Análisis functional del instrumental lítico tallado: un estudio preliminar. En: Torregrosa, P., Jover, F.J., López Seguí, E. (dirs.), Benàmer (Muro d'Alcoi, Alicante). Mesolíticos y neolíticos en tierras meridionales valencianas. Serie Trabajos varios SIP 112, 205-214.

Rozoy, J.G., 1978. Les derniers chasseurs: L'Epipaléolithique en France et en Belgique. Essai de synthèse. Bulletin de la Société Archéologique Champenoise, Charleville.

Soto, A., Alday, A., Mangado, X., Montes, L., 2016. Epipaleolítico y Mesolítico en la vertiente sur de los Pirineos desde la perspectiva de la industria lítica. Munibe Antropologia-Arkeologia 67, 295-312.

Tarriño, A., 2001. Procedencia de los sílex de la industria lítica del yacimiento de Aizpea (Navarra). En: Barandiarán, I., Cava, A. (dirs.), Cazadores y recolectores en el Pirineo navarro. El sitio de Aizpea entre el 8.000 y 6.000 años antes de ahora, 5161. Anejos de Veleia, Series Maior 10,

Utrilla, P., Montes, L., Mazo, C., Martínez Bea, M., Domingo, R., 2009. El Mesolítico geométrico en Aragón. In: Utrilla, P., Montes, L. (eds.), El mesolítico geométrico en la Península Ibérica, Monografías Arqueológicas. Prehistoria 44, 131-190.

Vaughan, P.C., 1985. Use-wear analysis of flaked stone tools. University of Arizona Press, Arizona.

Zapata, L., 2001. El uso de los recursos vegetales en Aizpea (Navarra, Pirineo occidental): La alimentación, el combustible y el bosque. En: Barandiarán, I., Cava, A. (dirs.), Cazadores-recolectores en el Pirineo navarro. El sitio de Aizpea entre 8.000 y 6.000 años antes de ahora. Anejos de Veleia, Series Maior 10, 325 